\section{Turismo Urbano na Cidade de São Paulo: a importância de alguns segmentos e seus reflexos na configuração do espaço}

Urban Tourism in the City of Sao Paulo:

the importance of some segments and its reflexions in the configuration of the destination

Reinaldo Miranda de Sá Teles

RESUMO: Este artigo resgata brevemente algumas questões urbanas que nortearam a ocupação do espaço de São Paulo a partir da área central da cidade. Aborda os negócios e os eventos como base para o turismo urbano, que indicam a relevância das estruturas herdadas no processo histórico, aliada à apropriação do espaço, e que desencadeiam formas de uso que agregam valor às várias atividades econômicas, entre as quais a turística. São Paulo é uma cidade que, embora capaz de captar um fluxo turístico, ainda carece de ações especificamente voltadas à organização do turismo.

PALAVRAS-CHAVE: turismo urbano; eventos; negócios; cidades; espaço; São Paulo.

ABSTRACT: This article brings out urban questions related to the space occupation in the city of Sao Paulo starting from its very central area. It is also about the businesses as well as events which are the base for urban tourism leading to the significance of its structure as a result of its historic process linked to the space appropriation. These which highlights forms of use, bringing out the value of numerous economic activities, including tourism. Sao Paulo is a

1. Doutor em Ciências da Comunicação, pela Escola de Comunicações e Artes da Universidade de São Paulo; mestre em Lazer e Turismo, pela ECA/USP; bacharel em Geografia, pela Faculdade de Filosofia, Letras e Ciências Humanas da Universidade de São Paulo; licenciado em Geografia, pela Faculdade de Educação da USP. Docente do Curso de Graduação em Turismo, da Escola de Comunicação e Artes da USP. No curso de Turismo da Faculdade Cásper Líbero, atua como coordenador de ensino e ministra as disciplinas Pesquisa em Turismo, Dimensão Espacial do Turismo I e II, e Representação Cartográfica no Turismo. Contato: reiteles@usp.br. city in which tourism flow is very constant, however there are more actions to be taken related to the tourism organisation yet.

KEYWORDS: urban tourism; events; business; cities; espace; Sao Paulo.

\section{Introdução}

A ocupação do espaço das cidades reflete a condição de produção a que ela está submetida. Assim, entender a evolução de algumas funções urbanas e o mecanismo de produção inserido nos limites territoriais das cidades requer uma análise integrada das diversas atividades ali presentes. Metrópoles são exemplos de uma variada gama de segmentos produtivos que desencadeiam forças que promovem o desenvolvimento urbano. Entre esses segmentos, destacam-se aqueles ligados aos setores de negócios e de eventos, dos quais se alimenta o turismo. São Paulo, por exemplo, é uma cidade que, resguardadas algumas limitações, já se destaca no campo do turismo urbano. Da mesma forma, o processo de globalização da economia se reflete em São Paulo, agregando significados na conformação urbana da cidade, tornando-a, assim, uma destinação turística de grande importância.

Determinadas questões relacionadas à estrutura urbana podem explicar o movimento de negócios realizados na cidade e seus reflexos no turismo urbano. Deste modo, desencadeiam o fortalecimento dos segmentos de negócios e de eventos, e contribuem para a organização do espaço. Essas atividades criam determinados serviços que, em algumas situações, podem ser classificados como a oferta turística. A leitura geográfica torna-se imprescindível para o entendimento do papel do turismo na configuração do espaço urbano.

\section{Algumas questões urbanas}

O turismo urbano na cidade de São Paulo fundamenta-se no processo de desenvolvimento que deixou estruturas e heranças socioculturais as quais, por sua vez, se apoiaram no quadro físico existente. A Geografia e a História ofereceram o arcabouço para a situação presente e, em parte, justificam o dinamismo da integração com outras partes do mundo que se reflete, de maneira acentuada, na trama urbana da cidade.

As atividades econômicas vêm construindo novos elementos para a composição da oferta no plano da cidade. Ao mesmo tempo, estruturas já consolidadas em pontos tradicionais apresentam-se obsoletas no plano de desenvolvimento econômico traçado pelo mercado global. 
Cordeiro destacou que, no plano geográfico, "São Paulo teve a trama urbana do período colonial substituída pela rede da economia de especulação do café, cujo nódulo se concentrava no centro da cidade de São Paulo" (Cordeiro, 1978: 8). Naquele momento, concentrava-se nesse nódulo toda a estrutura exigida para os grandes negócios realizados na cidade de São Paulo, então localizada no que hoje é chamado de CHT - Centro Histórico Tradicional ou Centro Velho da cidade.

À medida que a urbanização avançava, as estruturas já não atendiam às necessidades da nova fase do desenvolvimento que, então, se processava. Cordeiro observou que a "São Paulo dos bondes", na época geradora de importantes negócios, anulava-se diante das sucessivas intervenções para a adaptação do traçado urbano diante da produção de carros, que ocorria bem junto à cidade, e marcava o primeiro e grande mercado mais constante da era industrial: a indústria automobilística. A mesma autora afirmou que:

(...) na fase industrial, o crescimento de uma nova rede vai destruir a anterior para atender às exigências da economia de produção e de relação de um tipo novo e com tendência à absorção de funções urbanas, criando uma hipertrofia de aglomeração incompatível com a formação de redes no interior, caracterís-

tica das economias jovens dos países subdesenvolvidos (Cordeiro, 1978: 8).

No presente, quando se avalia a infra-estrutura das grandes cidades de maneira geral e, neste caso, a da cidade de São Paulo, verifica-se uma relação estreita entre eventos, negócios e turismo, que vai além do aproveitamento dos bens e serviços turísticos. Essa questão pode ser percebida na localização dos centros de eventos que fogem do circuito histórico tradicional.

No que se refere ao conjunto de atrativos histórico-culturais do Centro de São Paulo, observa-se que, mesmo considerando o esforço dos órgãos responsáveis pelo desenvolvimento do turismo na cidade e a tentativa de promoção dos atrativos do CHT, eles não são contemplados na lógica do mercado turístico local. As ações voltadas para esse segmento são pontuais e não contribuem para complementar o grande mercado de capitais, não concorrendo, assim, para a lógica da produção global. Nota-se que o CHT, que já foi o sujeito de uma história de glamour, e que na perspectiva urbana cumpria as exigências funcionais para esta categoria, está hoje numa condição decadente e pouco funcional no quadro de exigências para uma metrópole. Esse fato confirma as ações pontuais empreendidas pelo poder público e pela iniciativa privada.

Em outros pontos da cidade de São Paulo, ao contrário do que se verifica no CHT, em virtude da grande revolução na forma de produção, são os meios de hospedagem que revelam sinais de grandes transformações, inscrevendo-se no modelo globalizado, de maneira a atender à demanda de negócios e de eventos, consolidando uma oferta que segue padrões de qualidade internacional. Segundo Proserpio, nas últimas décadas, o setor de hospedagem vem contando com a forte e crescente participação das empresas multinacionais, organizadas em rede, que se beneficiam e, ao mesmo tempo, retroalimentam o processo de crescimento, oferecendo novos atrativos para o mercado de viagens (Proserpio, 2003).

Hoje, em São Paulo, a padronização hoteleira, que é ditada por uma lógica do mercado global, contribui para definir a ordem de ocupação dos novos centros que estão surgindo na cidade. Conforme destacaram Teles e Perussi, em São Paulo o turista não percebe a conectividade dos serviços, embora se tenha observado significativa oferta para o desenvolvimento da atividade turística, sobretudo no que se refere à rede hoteleira, que é resultado da própria condição do urbano que vive a cidade (Teles \& Perussi, 2007). Confirmando a proposição dos autores, a região central da cidade, que possui maior oferta de atrativos culturais, não é vista como um espaço funcional na lógica de produção global, excluindo, assim, o turismo como atividade capaz de suprir a localidade com referenciais que possam ser agregados no produto turístico dotado da capacidade de movimentar uma demanda por meio das agências receptivas, tendo como referencial o turismo cultural.

Somados ao segmento cultural, deve-se, também, considerar o turismo de negócios e o de eventos. Estes ocupam espaços que promovem e valorizam determinadas localidades, agregando naturalmente parte da oferta, integrando as áreas expandidas e alterando o limite dos espaços funcionais do município como um todo, de modo a beneficiá-las com as políticas urbanas traçadas pelo poder público.

Nesse sentido, observa-se que toda a infra-estrutura criada nas décadas de 1950 a 1960 vem passando por uma verdadeira revolução quanto ao seu ordenamento e à qualidade dos serviços oferecidos aos turistas que buscam a cidade São Paulo. O que pode justificar tal fato é o próprio desenvolvimento econômico, que tem apresentado novas condições ao ditar regras que primam, cada vez mais, por qualidade em relação aos serviços oferecidos. Pôde-se constatar que, recentemente, a estrutura produtiva e ocupacional da cidade sofreu profundas transformações, devido à abertura econômica, à globalização e aos novos processos produtivos que se alastram pelo mundo. A nova tecnologia fraciona o processo produtivo, tornando-o mais complexo, globalizado e fragmentado, ao exigir maior sofisticação e concentração nas atividades gerenciais. Com isso, ao mesmo tempo em que a cidade de São Paulo perde importância como centro industrial, ganha peso como centro de serviços de alta qualidade e complexidade. Esse fato fortalece o turismo enquanto setor da economia, revelando modalidades decorrentes de outras opções. 
Pode-se dizer que, dentre os setores de alta qualidade, destacam-se os financeiros, com elevado grau de concentração na cidade de São Paulo, principalmente os grandes bancos privados nacionais e internacionais, e as principais bolsas do país. A proximidade do mercado, o peso econômico do Estado e a localização dos principais prestadores de serviços empresariais estimulam a concentração dos negócios na capital paulista, justificando a presença das entidades representativas do setor financeiro e expressiva parcela dos grandes grupos empresariais, que se desdobram em outros investimentos, dadas às exigências da cidade.

\section{Os negócios e os eventos: bases para o turismo urbano}

Percebe-se que são as mudanças de ordem econômica que geram novas estruturas para as cidades, de maneira a enfatizar os segmentos que compõem o turismo urbano, incrementando, conseqüentemente, o fluxo de visitantes. No caso de São Paulo, conforme sinalizou a UBRAFE:

Centro econômico da América do Sul e do mais dinâmico e rico Estado brasileiro, a cidade de São Paulo, quarta maior cidade do mundo, é o principal portão de entrada de visitantes estrangeiros por via aérea do país, totalizando cerca de 1.345.000 desembarques por ano. O turismo de negócios colocou a cidade de São Paulo como ponto estratégico no MERCOSUL, em linha direta com as principais cidades do mundo.

No Brasil, as coisas acontecem primeiro em São Paulo. A cidade abriga o maior número de eventos a cada ano, totalizando 70 mil eventos, com número de participantes e visitantes superior a 15 milhões de pessoas, das quais mais de 10 milhões são habitantes da cidade e de sua área metropolitana, e 4,2 milhões são turistas [União Brasileira dos Promotores de Feiras - UBRAFE] (http//:www. cidadedesaopaulo.com, acesso em: 10 jan. 2006).

A grandeza do mercado de viagens a negócios é cada vez mais surpreendente. O efeito multiplicador que ocorre na cidade com a instalação de um banco ou de uma empresa pode atrair inúmeras outras, que passam a demandar por mais serviços. A necessidade de comunicação e transporte para outras localidades, sejam elas dentro ou fora do território em questão, promove outras viagens, além de demandar meios de hospedagem, restaurantes, locadoras de veículos, aeroportos etc.

No Brasil, segundo dados do Instituto Brasileiro de Turismo (EMBRATUR, 2006), pelo quinto ano consecutivo, observa-se a expansão de divisas do país por meio do turismo internacional. Dados do Banco Central revelaram recorde histórico dos gastos de turistas estrangeiros em visita ao Brasil, no ano de 2006: US $\$ 4,3$ bilhões ( $11,78 \%$ do que os US $\$ 3,9$ bilhões auferidos em 2005, até então a melhor marca da série iniciada em 1969). A receita obtida em 2006 é 116,02\% maior do que a de 2002 (US\$2 bilhões), o primeiro ano dessa seqüência positiva, seguindo-se US\$2,5 bilhões, em 2003, e US\$ 3,2 bilhões, em 2004.

No que concerne ao total de desembarques internacionais de passageiros, chegaram ao país 6.367 .179 passageiros $(6,20 \%$ a menos do que os 6.788 .233 passageiros registrados em 2005), apesar das adversidades da aviação civil ocorridas em 2006, como os problemas relacionados ao processo operacional nos aeroportos e a crise da VARIG.

Os números apresentados, embora representem o movimento nacional, mostram a dimensão do mercado de viagens, revelando uma vasta oferta turística em seus grandes centros econômicos, o que não impede maior investimento por parte dos órgãos competentes num possível "destino Brasil” para negócios. Trata-se de freqüentes usuários de equipamentos turísticos, que geram receitas e empregos para as cidades.

Em São Paulo, o mundo dos negócios ganhou impulso agregando o segmento de viagens a negócios, às viagens corporativas. O turismo de negócios passou a integrar a FAVECC - associação Fórum de Agências de Viagens Especializadas em Contas Correntes, que, além de propiciar facilidades aos grupos envolvidos, tais como organizar os deslocamentos e facilitar a locação de veículos, também pode disponibilizar serviços adicionais.

É importante ressaltar, com essa análise, que o turismo de negócios e o turismo de eventos contribuem para consolidar o turismo urbano. A força que tais segmentos têm na cidade está ligada aos negócios gerados em São Paulo, e o círculo se completa, pois esses segmentos também ampliam os negócios e os eventos, fortalecendo, assim, o turismo urbano.

As estruturas ofertadas pela metrópole, aliada às leis de mercado, implicam a multipolarização dos eventos da cidade. Segundo Dantas (2000), cada vez mais as feiras tradicionais são desdobradas em outras e os promotores investem em novos mercados. Do salão do automóvel surgiu uma feira de autopeças, e da composição do mesmo grupo nasceu uma feira de ônibus, a EXPOBUS. Diante do movimento observado na cidade, verifica-se que São Paulo está em primeiro lugar entre as cidades brasileiras que promovem feiras e eventos. Várias condições justificam o grande movimento de eventos na cidade, a saber:

- o aumento do número de empresários, centros de tecnologia, estudantes, universidades e centros médicos;

- o aumento no fator negócios, em variados setores 
- a divulgação da cidade enquanto destino de negócios;

- os mercados especializados (compras na rua 25 de Março e em shopping centers) (Dantas, 2000).

A partir dos itens apontados, pode-se dizer que o turismo de eventos, enquanto segmento do turismo urbano, apresenta potencial de desenvolvimento e crescimento bastante expressivo para a cidade de São Paulo. Estudos realizados confirmam tal constatação. A esse respeito, Canton (2002) afirmou:

Percebemos que, hoje, muitas cidades brasileiras estão despertando para este novo nicho de mercado, que se destaca em decorrência da grande receita que deixa em localidades receptoras e sedes dos eventos. É notório que, no mundo todo, o turismo de eventos tenha se caracterizado como o mais lucrativo filão do mercado, tanto por seu potencial de ampliar a demanda na alta estação quanto por ser a alternativa mais viável para superar o vazio da baixa estação (Canton, 2002: 88).

O que beneficia as localidades de maneira geral é o fato de que, na qualidade de agentes captadores de fluxo turístico, os eventos diferenciam-se de outros atrativos, pois podem ser criados e moldados de forma a atender às necessidades de suas demandas específicas, bem como as dos espaços e das localidades que os abrigam. Esse fato ainda não é peculiar à cidade de São Paulo, por ela não ter organizado seus atrativos de maneira a torná-los interessantes para quem a visita.

Conforme afirmou Canton, as possibilidades de criação de eventos são ilimitadas, podendo ser realizados para atrair público específico e servir como atrativos adicionais numa localidade turística, incrementando ou fomentando seus fluxos. Canton destacou a ampla capacidade de criação desse segmento: "Os eventos são tão variados quanto a criatividade de quem os provoca. A atividade moderna, em sua múltipla diversidade, faz com que surjam eventos de todos os tipos e qualidades" (Canton, 2001:37).

Diante das questões colocadas, nota-se que tanto o turismo de eventos como o turismo de negócios estão surgindo em cidades que se configuram em diferentes escalas, e especialmente em cidades com as características de São Paulo.

No campo teórico, e segundo Lefébvre, o fenômeno urbano surpreende por sua enormidade; sua complexidade ultrapassa os meios do conhecimento e os instrumentos da ação prática. Ele torna quase evidente a teoria da complexidade, segundo a qual os fenômenos sociais vão de certa complexidade (relativa) a uma complexidade maior (Lefèbvre, 2004: 51).

É importante destacar que, em várias cidades de todo o mundo, a captação e a promoção de eventos vêm sendo consideradas as atividades que mais retorno econômico e social oferecem às localidades promotoras. Isso se dá em função do próprio movimento financeiro, ainda como resquício da atividade industrial, que desencadeia atividades no setor terciário, no qual se enquadra o turismo. A EMBRATUR apontou vários benefícios que esse segmento promove para as cidades:

- o turismo de eventos ajuda a equilibrar oferta e demanda, pois a realização dos eventos concentra-se na baixa estação; a ocupação na baixa temporada é vantajosa para empresários e para turistas;

- por ocorrer normalmente em baixa temporada e por receber um número predefinido de participantes, diz-se que o turismo de eventos faz com que o turismo seja praticado de forma mais consciente e responsável;

- a antecedência com que se decide a realização dos eventos e a sua divulgação permite aos fornecedores de serviços turísticos a previsão dessa demanda e, com isso, eles podem se preparar melhor para recebê-la;

- o investimento na promoção do local é menor e mais direcionado do que no caso do turismo de lazer, pois não é necessário atingir cada turista ou cada pequeno grupo de turista, e sim apenas a empresa organizadora do evento;

- a realização de eventos enriquece a vida cultural da cidade, tanto por receber as autoridades e experts em determinada área como por incrementar a produção e a valorização de membros da comunidade local;

- o turista de eventos permanece na localidade de quatro a cinco dias, gastando, em média, US\$240,00 - ao passo que o turista de lazer gasta três vezes menos, e seu tempo de permanência é de três dias;

- o turismo de eventos vem crescendo de forma ininterrupta; de cada 70 mil congressosocorridos ao ano no mundo, 2 mil são realizados no Brasil (EMBRATUR, 2002).

Os dados e números apontados pela EMBRATUR confirmam a relevância dos eventos para o turismo nas localidades, mostrando os efeitos no fluxo turístico, além da complexidade e multiplicidade das ações desenvolvidas para incrementar e promover os eventos. Tais características são peculiares ao fenômeno urbano, do qual se apropria o turismo. Pode-se, assim, estabelecer uma analogia com a proposição feita por Lefebvre, quando este destacou que o fenômeno urbano surpreende por sua enormidade. No caso da cidade de São Paulo, Teles e Perussi apontaram que a capacidade turística da cidade de São Paulo mostra que a infra-estrutura hoteleira e para eventos deve ser considerada fundamental para a gestão do turismo e, além disso, que as ofertas cultural, gastronômica e de lazer 
mostram-se altamente diversificadas e ricas (Teles \& Perussi, 2007), fato que pode contribuir para a gestão do turismo.

\section{São Paulo: a fragilidade da oferta e a produção de roteiros culturais}

Percebe-se que o turismo de eventos e o turismo de negócios são segmentos que fortalecem São Paulo, dadas às características urbanas dessa metrópole. A região de São Paulo, polarizada pela capital, é formada por 39 municípios, constituindo uma enorme mancha urbana, que reúne todas as condições favoráveis ao desenvolvimento do turismo de negócios. Conforme apontou Braga, as condições incluem:

- sistema de transportes, que, a partir da capital, se irradia em todas as direções;

- aeroportos;

- estações rodoviárias;

- serviços especializados de táxi, heliportos, motoboys, além de metrô e outros;

- comércio e serviços especializados em geral, que primam pela diversidade;

- hospedagem diferenciada e de vários níveis (Braga, 2005: 32).

Para Braga:

(...) a extraordinária efervescência de São Paulo identifica-se com a imagem de metrópole agitada, geralmente associada à avenida Paulista, local de grande concentração das instituiçōes financeiras do país, das principais federaçōes de empresários e industriais do Brasil. Na avenida Paulista, manifestaçōes e eventos políticos e socioculturais acontecem, reunindo milhares de pessoas. A esta artéria paulistana, marcada pela expressiva realização de negócios, outras se juntam, como a região da avenida Engenheiro Luís Carlos Berrini e outros centros comerciais distribuídos pelos diversos distritos do município (Braga, 2005: 34).

Dados do SPC\&vB, de 2005, revelam que a infra-estrutura turística da capital paulistana apresenta 12,5 mil restaurantes, 15 mil bares, 72 shopping centers, 550 hotéis, 41 áreas de patrimônio, 41 festas populares, 13 eventos permanentes, 9 casas de espetáculos, 7 estádios de futebol e 4 parques temáticos, 120 teatros com mais de 600 peças por ano. Esses números indicam que São Paulo pode ser considerado o maior pólo cultural do País (SPC\&VB, 2005).

O crescimento urbano gera mudanças como resultado do dinamismo social, econômico e cultural. Rolnick, em sua obra O que é cidade?, revelou o dinamismo das cidades, e afirmou serem elas aceleradoras de partículas e fontes de inovação artística e tecnológica. É nelas que tudo acontece, e, por isso, não desaparecerão jamais; mas elas precisam mudar, e já estão mudando (Rolnick, 1997).

No que tange ao turismo, resultados de algumas pesquisas encomendadas pelo SPC\&VB confirmaram a condição específica do turismo receptivo em São Paulo. Estas pesquisas indicaram que, em 2005, os serviços de recepção ao visitante na metrópole estão muito pouco estruturados e as opções de roteiros são muito restritas. Esses dados mostram que importantes atrativos encontram-se totalmente desconectados com a proposta de roteiros clássicos que são oferecidos pelas agências e/ou operadoras da cidade. Outra questão importante é a tentativa de retirar o turista da cidade, redirecionando-o para municípios vizinhos. Tal descompasso se confirma devido à falta de conectividade existente entre a oferta gerada para a cidade numa escala temporal e a valorização exclusiva de espaços específicos que atendem às necessidades de um mercado de negócios na esfera global.

De acordo com Navarro (2006), os roteiros divulgados pelas agências e/ou operadoras ${ }^{2}$ apresentam o mesmo itinerário, o que significa que os pontos visitados, embora necessitem de mais qualidade enquanto elementos que compõem o produto turístico da cidade, já se apresentam como atrativos consolidados. Esta condição confirma a falta de gestão entre os roteiros convencionais e toda a infraestrutura técnica já estabelecida e digna de uma metrópole.

\section{Roteiros turísticos de agências receptivas na cidade de São Paulo}

\section{Roteiro}

\section{City tour de 4, 6 ou 8 horas}

Passeios maravilhosos e culturais pela cidade de São Paulo: centro histórico, bairro oriental (Liberdade), Higienópolis, MASP, avenida Paulista, Jockey Clube, Instituto Butantã, Parque do Ibirapuera, Museu do Ipiranga etc

2. Aeroporto Express, Andanças Tur, Check Point, Circuito São Paulo, Coopline Tur, Costa Aguiar, Easygoing, Fasttrans, Go In, Goltour, Graffit, Number One Tours, GRP Brasil, RMB, Santa Rita Turismo, Urben Turismo, Relax, Tayar Turismo e Terra Nobre. 


\section{2o Roteiro}

\section{Tour by night}

Gastronomia de alta qualidade, com shows de mulatas, músicos e bailarinas em casas noturnas especializadas, incluindo desfile de fantasias de carnaval.

\section{3o Roteiro}

\section{Turismo cultural de 4 ou 8 horas}

Visita a vários museus, como Pinacoteca, MASP, MAC, MAM, Memorial da América Latina, Museu do Ipiranga e Museu de Arte Sacra, entre outros.

\section{4ำ Roteiro}

\section{Turismo nas praias}

Passeios em Santos e Guarujá, com vista panorâmica da Serra do Mar e da costa marítima, e parada para descanso ou banho de mar.

\section{5o Roteiro}

\section{Turismo em shoppings}

Saídas para compras em grandes shoppings de São Paulo, como Ibirapuera, Iguatemi e Eldorado, ou ruas de comércios especializados.

Fonte: Roberta Campos Navarro - 2006.

O que se observa é que as agências e/ou operadoras, de um modo geral, gerenciam roteiros que são procurados por turistas e, também, por alguns moradores da cidade. A grande dificuldade em ofertar esse produto está no próprio mecanismo de desigualdade ao qual o espaço urbano é submetido, pois o poder financeiro que constrói lugares é pautado pela lógica do mercado globalizado, mercado este que a cidade de São Paulo, assim como várias cidades da América Latina, reproduz conforme a especialização do sistema de produção ditado pelos mercados superiores. Assim, a gestão dos roteiros elaborados pelas operadoras comprometidas com o receptivo da cidade de São Paulo não conta com o apoio de ações que deveriam ser definidas nas políticas e nos programas que poderiam orientar a organização dos espaços da cidade, a fim de valorizar e preservar seu patrimônio, garantindo a preservação da identidade da cidade.

\section{Considerações finais}

Com base nas questões levantadas no decorrer do texto, percebe-se que o turismo urbano na cidade de São Paulo não aconteceu por acaso: ele é resultado do processo histórico e de questões geográficas, econômicas, sociais e culturais que atuaram em diversos momentos, e com intensidades variadas, agindo como forças de atração para formar diversos segmentos, entre os quais destacam-se o turismo de negócios e o turismo de eventos. A expansão urbana, representada por diversos fatores, entre os quais o incremento do setor terciário, concorre, ainda hoje, para formar novos espaços na cidade, marcados pelo setor de serviços, que somam para a efetivação do turismo urbano.

A cidade de São Paulo, assim como toda grande cidade, pode ser apontada como destino preferencial para o turismo urbano, pois, além dos atrativos culturais que pode oferecer, tem no movimento de eventos e negócios o elemento-chave para a identificação dessa modalidade, visto que são esses segmentos que contribuem para o fortalecimento da infra-estrutura, que dá suporte a essa categoria.Entender o turismo urbano na cidade de São Paulo representa um desafio necessário na busca por uma forma de gestão capaz de aprimorar essa modalidade.

O espaço urbano revela a ordem estabelecida pelos setores da economia, ao longo do tempo e, sendo assim, questões relacionadas ao mercado de turismo devem ser claramente elucidadas. Iniciativas da Associação Viva o Centro, que busca a valorização do patrimônio e o resgate da memória da cidade, devem ser entendidas como possibilidades de valorização do espaço urbano e, conseqüentemente, da atividade turística.

De maneira geral, diante das mudanças estruturais das cidades, o turista que chega a negócios ou para participar de eventos depara-se com uma infinidade de produtos, cuja formatação só é possível devido à gama de possibilidades presentes no espaço urbano. No caso da cidade de São Paulo, devido à falta de gestão da atividade, essa ainda não é uma realidade. Entretanto, algumas ações pontuais, e também o esforço empreendido por agências e operadoras empenhadas no receptivo em São Paulo, já apontam para o amadurecimento dessa idéia.

\section{Referências bibliográficas}

BRAGA, Debora C. 2005. À margem das feiras de negócios - uso do tempo livre do turista em São Paulo. Tese (Doutorado) - Departamento de Relaçōes Públicas, Propaganda e Turismo da Escola de Comunicaçōes e Artes da Universidade de São Paulo.

CANTON, Marisa Antonia. 2002. Eventos - ferramenta de sustentação para as organizações do terceiro setor. São Paulo: Roca. 
CORDEIRO, Helena K. 1978. O centro da metrópole paulistana: expansão recente. Tese (Doutorado) - Faculdade de Filosofia, Letras e Ciências Humanas da Universidade de São Paulo. . 1980. O centro da metrópole paulistana: expansão recente. São Paulo: Universidade de São Paulo, Instituto de Geografia.

1993. A cidade mundial de São Paulo e a recente expansão de seu centro metropolitano. In: SANTOS, M. et al. O novo mapa do mundo: fim do século e globalização. São Paulo: Hucitec/Associação Nacional de Pós-graduação e Pesquisa em Planejamento Urbano e Regional.

DANTAS, Vera. 2000. Feira de negócios: São Paulo tem 90\% do mercado. O Estado de S. Paulo, São Paulo, 6 nov.

EMBRATUR. Instituto Brasileiro de Turismo. 2006. Turismo urbano e turismo em cidades. Disponível em: <http://www.turismo.gov.br/index.html>. Acesso em: 10 jan. 2006.

LEFÈBVRE, Henri. 1972. La vida cotidiana do mundo moderno. Madrid: Alianza Editorial. 1974. La production de l'espace. Paris: Anthropos.

2004. A revolução urbana. Belo Horizonte: Editora UFMG.

PROSERPIO, Renata. 2003. Oavanço das redes hoteleiras internacionais no Brasil 1994-2002. Tese (Doutorado em Ciências da Comunicação) - Departamento de Relaçōes Públicas, Propaganda e Turismo, da Escola de Comunicações e Artes da Universidade de São Paulo.

ROLNICK, Raquel. 1990. São Paulo, crise e mudança. São Paulo: Brasiliense. 1997. A cidade e a lei. São Paulo: Studio Nobel/FAPESP.

SĀO PAULO CONVENTION \& VISITORS BUREAU. 2005. Plano de marketing do turismo da cidade de São Paulo. Disponível em: <www.visitesaopaulo.com>. Acesso em: 10 abr.

TELES, Reinaldo Miranda de Sá \& PERUSSI, Regina Ferraz. 2007. A importância da comunicação para a consolidação da imagem do produto turistico São Paulo. NP 19 - Comunicação, Turismo e Hospitalidade. ENCONTRO DOS NÚCLEOS DE PESQUISA DO XXX CONGRESSO BRASILEIRO DE CIÊNCIAS DA COMUNICAÇĀO, 7. 29 de agosto a 2 de setembro de 2007, Santos (SP).

Recebido em: 28/11/2006.

Aprovado em: 04/03/2007. 